\title{
Identification of Crack in Reinforced Concrete Beam Subjected to Static Load Using Non-linear Finite Element Analysis
}

\author{
Abdulsamee Halahla ${ }^{a^{*}}$ \\ ${ }^{a}$ Fahad Bin Sultan University, P.O Box 15700, Tabuk, Saudi Arabia.
}

Received 09 March 2019; Accepted 20 June 2019

\begin{abstract}
Experimental testing was used widely as a means to investigate the behavior of these individual elements and the effects of concrete strength under different loading types. While this method represents real life responses, it is very time consuming and the use of materials can be quite costly. Recently, the use of finite element analysis (FEA) has increased due to advances in knowledge and the capabilities of computer hardware and software. The utilization of computer software to model the structural elements has become much faster and extremely cost-effective. The finite element software ANSYS 11.0 is used for modeling and analysis by conducting non-linear static analysis. This research work used nonlinear finite element analysis for a reinforced concrete beam in order to show the potential of the FEA for studying the behavior of reinforced concrete elements, and to understand their load-deflection response along with the crack evolution. For concrete a solid 65 element was used, while for the reinforcement steel bar link 8 elements were used. For the material constitutive model linear and multi-linear behavior for concrete were considered, while linear and bilinear behavior were considered for the reinforcement bar. A reinforced concrete beam model is studied and compared with experimental data from the literature. The characteristic points on the load-deflection response curve predicted using finite element analysis, were compared to the theoretical limit (hand-calculated) results. Conclusions were then drawn as to the accuracy of using finite element modeling for the analysis of reinforced concrete elements. The results showed a good match to experimental and hand calculations.
\end{abstract}

Keywords: Concrete; Load Deflection; Crack; Non-linear Analysis; Finite Element Analysis; ANSYS.

\section{Introduction}

The use of FEA has been the preferred method to study the behavior of concrete (for economic reasons). Many studies investigated the feasibility of the use of finite element analysis in order to investigate the behaviour of reinforced concrete elements [1-5]. Willam and Tanabe [6], contain a collection of papers concerning the finite element analysis of reinforced concrete structures This collection contains areas of study such as: the seismic behavior of structures, the cyclic loading of reinforced concrete columns, the shear failure of reinforced concrete beams, and concrete steel bond models. Shing and Tanabe [7], also put together a collection of papers dealing with the inelastic behavior of reinforced concrete structures under seismic loads. The monograph contains contributions that outline the applications of the finite element method for studying post-peak cyclic behavior and the ductility of reinforced concrete columns, along with the analysis of reinforced concrete components in bridge seismic structures. Kaya and Arslan [8] studied the analytical modeling of post-tensioned precast beam-to-column connections. The finite element analysis software, ANSYS, is used to simulate a 3D nonlinear finite element model for both precast and cast-in-place beam-to-column connections under

* Corresponding author: ahalahla@fbsu.edu.sa

http://dx.doi.org/10.28991/cej-2019-03091359

(C) 2019 by the authors. Licensee C.E.J, Tehran, Iran. This article is an open access article distributed under the terms and conditions of the Creative Commons Attribution (CC-BY) license (http://creativecommons.org/licenses/by/4.0/). 
the effect of a cyclic load to investigate the connection strength, behavior and stiffness. The elastic-perfectly plastic model of the mild and pre-stressed steel and the link8 element was considered, while for the concrete material the Hognestad model was used considering multi-linear isotropic material. In addition, the Willam-Warnke failure model was used and the solid65 element with eight nodes was considered for the concrete and reinforced concrete since this element has the properties of cracking under tension, creep, crushing under compression and plastic deformation. The smeared crack model was selected to define the cracked concrete, moreover for the place of end support and the place of the applied load the solid 45 element was used to prevent the crushing of concrete. The figure below shows the element type used in the finite element model [9].

The finite element analysis software, ANSYS, and, SAP2000, are used to investigate the benefit of strengthening the beam-column joint of an ordinary RC frame by FRP sheets by CFRP web-bonding of the joint in order to improve the seismic performance and behavior factor $\mathrm{R}$. The model takes into account the geometric nonlinearities and the material inelasticity. For concrete material the Willam-Warnke failure model was used, and the solid65 element with eight nodes was considered for the concrete, while the FRP was considered as an anisotropic material, as well as a bilinear material, and solid45 element with 8-nodes was used, in addition the link8 element was used for steel bars. The nonlinear static pushover analysis was carried out using the SAP2000 finite element software, under the effect of lateral load, and the nonlinear link element was used in order to consider the additional stiffness provided by the web-bond FRP sheet. In the study by Ravi and Arulraj [10] the finite element analysis software, ANSYS, was used to simulate a beam-column joint retrofitted with carbon fiber reinforced polymer sheets which was subjected to a static load at the cantilever beam. To study the performance of the CFRP in retrofitting the beam-column two models were used: the first one without the CFRP and the second one with CFRP wrapped at the beam-column joint. Both ends of the column were considered to be a hinge and the static load was applied at the end of the beam. The concert materials represented by the solid65 element and the ink8 element were used for reinforced concrete, while for the warp CFRP the solid 45 element was used [11].

The finite element analysis software, ANSYS (ANSYSWORKBENCH), was used to investigate the fire performance of the CFRP-strengthened member and its resistance to heat transfer, and the study was done for an RC Tbeam exposed to ASTM E119 standard fire, since for symmetry only a quarter of the beam was modeled. The elasticperfectly plastic with the hardening model was used for the steel (bilinear stress-strain curve), while for the concrete material the standard nonlinear constitutive model based on the Willam-Warnke model was used. Due to the transient thermal analysis the thermal element solid70 with 3D eight nodes was used for the concrete and the thermal element link33 with 3D uniaxial 2-node conduction was used for the reinforced steel bar. These thermal elements were converted to structural elements as per the following: i) for the concrete material thermal element solid70 to structural element solid 65 ii) for the FRP thermal element solid70 to structural element solid46 iii) for the steel thermal element solid33 to structural element link8 design, the analysis of reinforced concrete beam-column bridge connections, and the modeling of the shear behavior of the reinforced concrete bridge.

Shaker and Kamonna [12] studied the behavior of reinforced concrete beams strengthened with prestress CFRP sheets using a nonlinear finite element analysis. This paper is a study of reinforced concrete beams using finite element analysis to understand the response of reinforced concrete beams subjected to transverse loading. The objective of this study is to investigate and evaluate the use of the potential of the FEA to investigate the behavior of reinforced concrete beams and to understand their load-deflection response, along with the crack evolution. A mild-steel reinforced concrete beam with flexural and shear reinforcement was analyzed to failure and compared to the experimental results obtained by Buckhouse [13]. A calibration model using a commercial finite element analysis package (ANSYS) was set up and evaluated using experimental data. A mild-steel reinforced concrete beam with flexural and shear reinforcement was analyzed to failure and compared to the experimental results to calibrate the parameters in ANSYS for later analysis.

\section{Review of the William Waranke Model and Surface Failure for Concrete}

The triaxial failure surface of unconfined plain concrete was developed by Willam and Warnke [14]. As shown in Figure 1 the failure surface is represented in the principal stress-space because the stress components are ordered according to $\sigma_{1} \geq \sigma_{2} \geq \sigma_{3}$. The mathematical model considers the sextant of the principal stress space as shown in Figure 1. The failure surface is separated into deviatoric (change in shape) sections and hydrostatic (change in volume). The deviatoric section in Figure 2 lies in a plane normal to the equisectrix (dashed line in Figure 2). The hydrostatic section forms a meridianal plane which contains the equisectrix $\sigma_{1}=\sigma_{2}=\sigma_{3}$ as an axis of revolution (see Figure 1). 


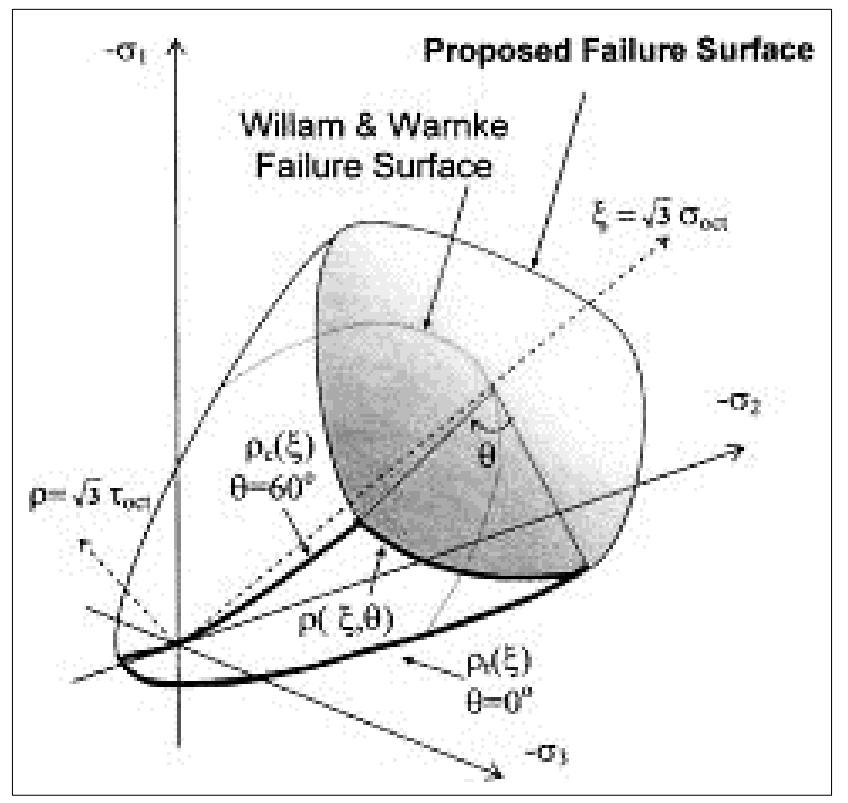

Figure 1. Failure surface of plain concrete under triaxial conditions [14]

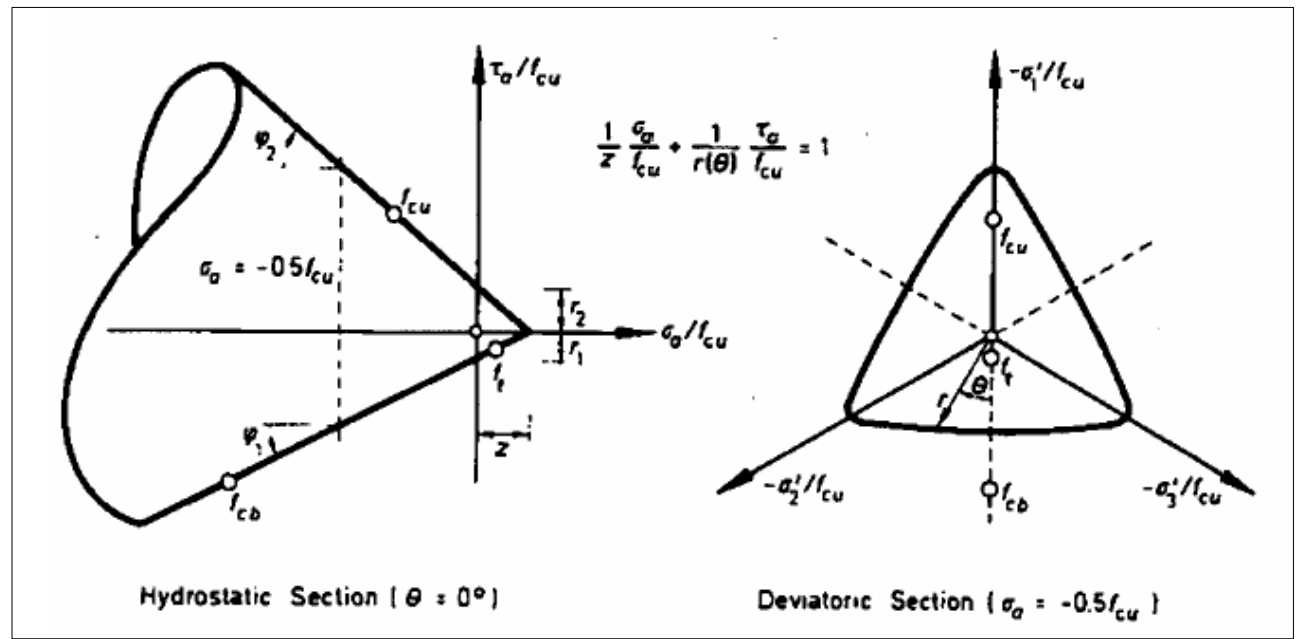

Figure 2. Three parameter model [14]

The polar coordinates $r$, and $\theta$ were used to describe the deviatoric trace where $r$ is the position vector locating the failure surface with angle, $\theta$. The failure surface is defined as:

$$
\frac{1}{z} \frac{\sigma_{a}}{f_{c u}}+\frac{1}{r(\theta)} \frac{\tau_{a}}{f_{c u}}=1
$$

Where $\sigma_{\mathrm{a}}$ and $\tau_{\mathrm{a}}=$ average stress components, $\mathrm{z}=$ apex of the surface, $\mathrm{f}_{\mathrm{cu}}=$ uniaxial compressive strength. The opening angles of the hydrostatic cone are defined by $\phi_{1}$ and $\phi_{2}$. The free parameters of the failure surface $\mathrm{z}$ and $\mathrm{r}$, are identified from the uniaxial compressive strength $\left(f_{c u}\right)$, the biaxial compressive strength $\left(f_{c b}\right)$, and the uniaxial tension strength $\left(f_{t}\right)$.

The Willam and Warnke [14], mathematical model of the failure surface for the concrete has the following advantages: i) close fit of experimental data in the operating range; ii) simple identification of model parameters from the standard test data; iii) smoothness (e.g. continuous surface with continuously varying tangent planes); and iv) convexity (e.g. monotonically curved surface without inflection points). Based on the above criteria, a constitutive model for the concrete suitable for FEA implementation was formulated. This constitutive model for concrete based upon the Willam and Warnke [14], model assumes an appropriate description of the material failure. The yield condition can be approximated by three or five parameter models distinguishing linear from non-linear and elastic from inelastic deformations using the failure envelope defined by a scalar function of stress $\mathrm{f}(\sigma)=0$ through a flow rule, while using incremental stress-strain relations. The parameters for the failure surface can be seen in Figure 2. During transition from elastic to plastic or elastic to brittle behavior, two numerical strategies were recommended: proportional penetration, 
which subdivides proportional loading into an elastic and inelastic portion which governs the failure surface using integration, and normal penetration, which allows the elastic path to reach the yield surface at the intersection with the normal, thereby solving a linear system of equations. Both of these methods are feasible and give stress values that satisfy the constitutive constraint condition. From the standpoint of computer applications the normal penetration approach is more efficient than the proportional penetration method, since integration is avoided.

\section{Material Constitutive Model for Concrete}

\subsection{Concrete in Compression}

For concrete material, the Solid65 elements were used. The Solid65 element is shown in Figure 3. In order to properly model the concrete material linear isotropic and multilinear isotropic material properties were used. The multilinear isotropic material uses the von Mises failure criterion, along with the Willam and Warnke (1974) model, to define the failure of the concrete. $\mathrm{E}_{\mathrm{X}}$ is the modulus of elasticity of the concrete $\left(\mathrm{E}_{\mathrm{c}}\right)$, and $\mathrm{PR}_{\mathrm{XY}}$ is the Poisson's ratio $(v)$. The modulus was based on the equation,

$$
E_{c}=5700 \sqrt{f_{c}^{\prime}}
$$

With a value of $\mathrm{f}$ 'c equal to $4,800 \mathrm{psi}$. The Poisson's ratio was assumed to be 0.3 . The compressive uniaxial stressstrain relationship for the concrete model was obtained using the following equations to compute the multilinear isotropic stress-strain curve for the concrete [15].

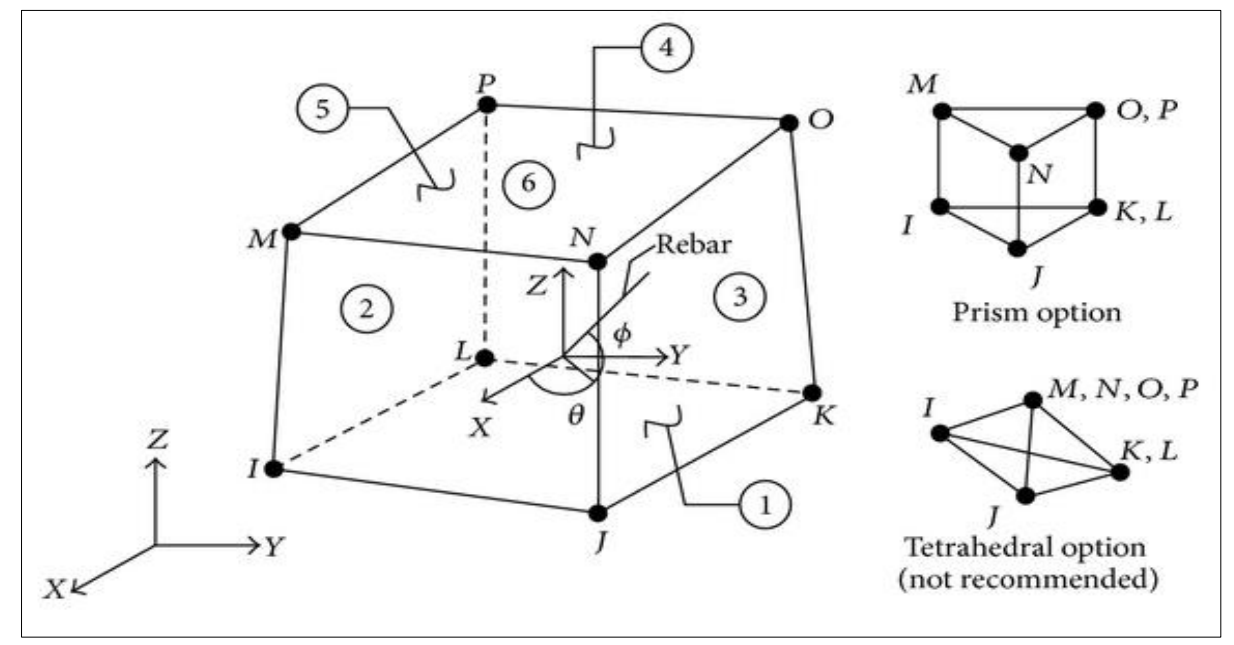

Figure 3. Solid 65: 3D reinforced concrete solid [16]

$$
\begin{aligned}
& f=\frac{E_{c} \varepsilon}{1+\left(\frac{\varepsilon}{\varepsilon_{0}}\right)^{2}} \\
& \varepsilon_{0}=\frac{2 f_{c}^{\prime}}{E_{c}} \\
& E_{c}=\frac{f}{\varepsilon}
\end{aligned}
$$

Where:

$\mathrm{f}=$ stress at any strain $\varepsilon$, psi

$\varepsilon=$ strain at stress $f$

$\varepsilon_{0}=$ strain at the ultimate compressive strength $f_{c}^{\prime}$

The multilinear isotropic stress-strain implemented requires the first point of the curve to be defined by the user. It must satisfy Hooke's Law;

$$
E=\frac{\sigma}{\varepsilon}
$$




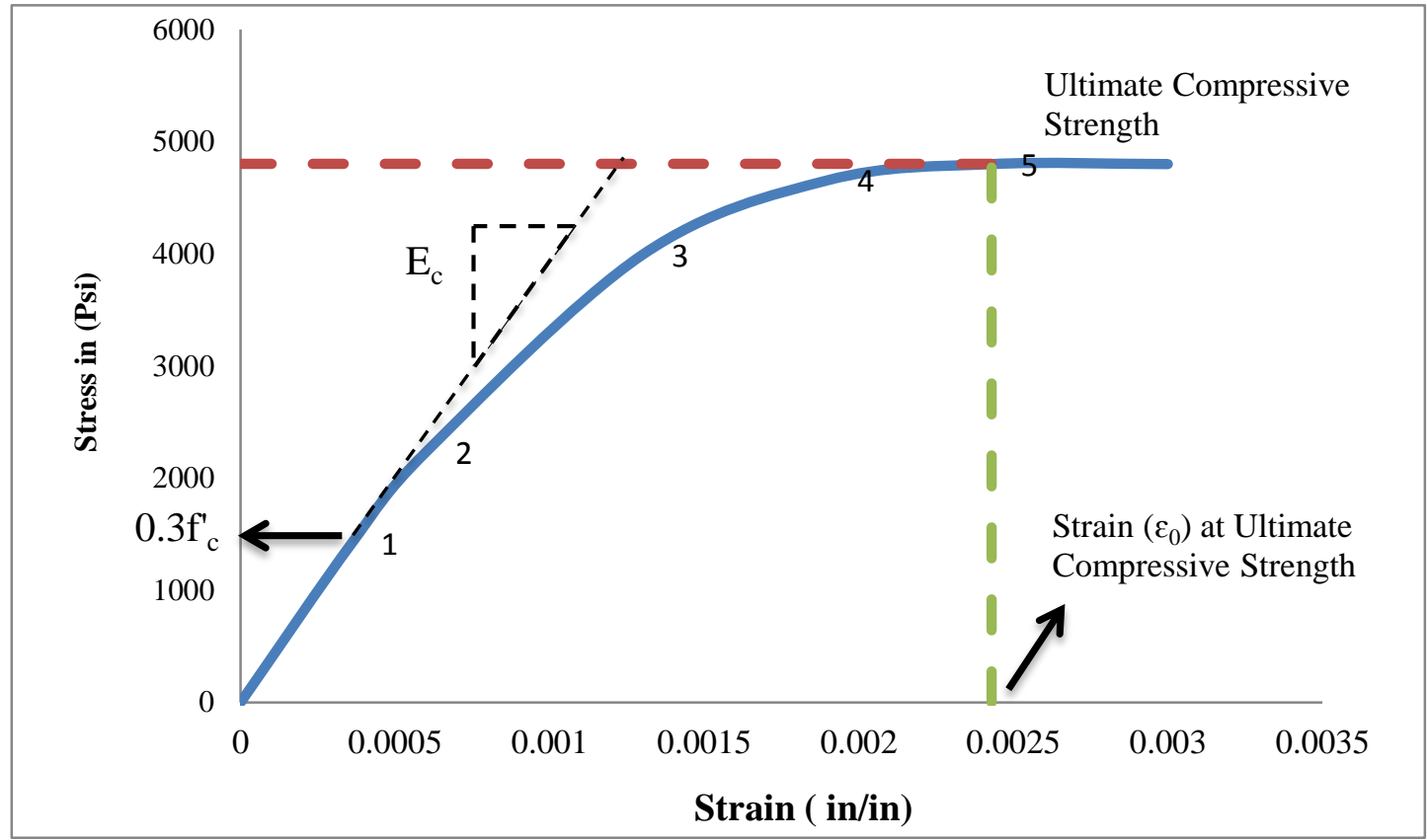

Figure 4. Uniaxial stresses-strain curve for concrete by Kachlakev et al. [17]

Figure 4 shows the stress-strain relationship used for this study and is based on work done by Kachlakev et al. [17]. Point 1, defined as $0.30 f_{c}^{\prime}$, is calculated in the linear range (Equation 4). Points 2, 3, and 4 are calculated from Equation 2 with $\varepsilon_{0}$ obtained from Equation 3. Strains were selected and the stress was calculated for each strain. Point 5 is defined at $f_{c}^{\prime}$ and $\varepsilon_{0}=0.003 \mathrm{in} / \mathrm{in}$ indicating traditional crushing strain for unconfined concrete. Implementation of the Willam and Warnke (1974) material model in ANSYS requires that different constants be defined.

These 9 constants are:

1. Shear transfer coefficients for an open crack;

2. Shear transfer coefficients for a closed crack;

3. Uniaxial tensile cracking stress;

4. Uniaxial crushing stress (positive);

5. Biaxial crushing stress (positive);

6. Ambient hydrostatic stress state for use with constants 7 and8;

7. Biaxial crushing stress (positive) under the ambient hydrostatic stress state (constant 6);

8. Uniaxial crushing stress (positive) under the ambient hydrostatic stress state (constant 6);

9. Stiffness multiplier for cracked tensile condition.

\subsection{Tensile Behaviour of Concrete}

Until the crack occurs, the initial tangent modulus $E_{c}$ is used to find the maximum positive (tensile) stress. After concrete cracking takes place, a smeared crack model is used to represent the discontinuous macro-crack behavior. This cracked concrete can still carry some tensile stress perpendicular to the crack, which is termed 'tension stiffening'. The tension stiffening factor $\left(\alpha_{m}\right)$, Figure 5, was assumed to be 0.6. In this work, a simple descending line is used to model this tension stiffening phenomenon. 


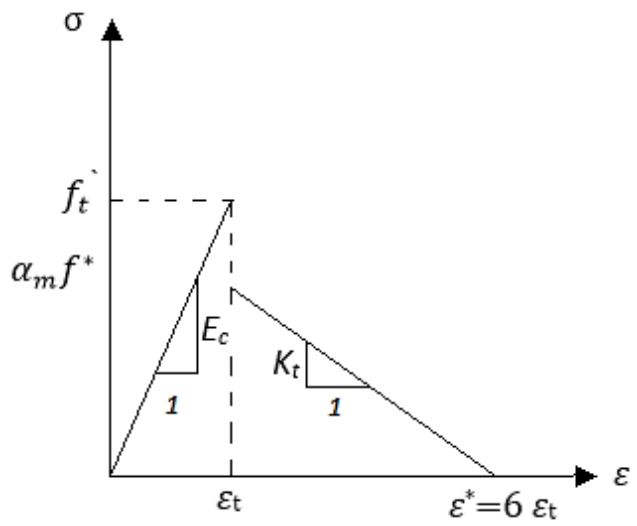

Figure 5. Tension stiffening model [18]

\subsection{Crack Model for Concrete}

In concrete, when the tensile stress in the principal direction exceeds the tensile strength, $f_{t}$, of concrete, tensile failure occurs [18]. After the crack forms, both normal and shear stiffness are reduced. Typical shear transfer coefficients range from 0.0 to 1.0, with 0.0 representing a smooth crack (complete loss of shear transfer) and 1.0 representing a rough crack (no loss of shear transfer). The shear transfer coefficients for open and closed cracks were determined using the work of Kachlakev et al. [17], as a basis. Convergence problems occurred when the shear transfer coefficient for the open crack dropped below 0.2. No deviation of the response occurs with the change of the coefficient. Therefore, the coefficient for the open crack was set to 0.3 (Table 1). The uniaxial cracking stress was based upon the modulus of rupture. This value is determined using,

$$
f_{r}=7.5 \sqrt{f_{c}^{\prime}}
$$

The uniaxial crushing stress in this model was based on the uniaxial unconfined compressive strength $\left(f_{c}^{\prime}\right)$ and is denoted as $\mathrm{ft}$. It was entered as -1 to turn off the crushing capability of the concrete element as suggested by past researchers [17]. Convergence problems have been repeated when the crushing capability was turned on. The biaxial crushing stress refers to the ultimate biaxial compressive strength $\left(f_{c b}^{\prime}\right)$. The ambient hydrostatic stress state is denoted as $\sigma_{h}$. This stress state is defined as:

$$
\sigma_{h}=\frac{1}{3}\left(\sigma_{x p}+\sigma_{y p}+\sigma_{z p}\right)
$$

Where $\sigma_{x p}, \sigma_{y p}$ and $\sigma_{z p}$ are the principal stresses in the principal directions. The biaxial crushing stress under the ambient hydrostatic stress state refers to the ultimate compressive strength for a state of biaxial compression superimposed on the hydrostatic stress state $\left(f_{1}\right)$. The uniaxial crushing stress under the ambient hydrostatic stress state refers to the ultimate compressive strength for a state of uniaxial compression superimposed on the hydrostatic stress state $\left(f_{2}\right)$. The failure surface can be defined with a minimum of two constants, $f_{t}$ and $f_{c}^{\prime}$. The remainder of the variables in the concrete model are left to default based on these equations [19]:

$$
\begin{aligned}
& f^{\prime}{ }_{c b}=1.2 f^{\prime}{ }_{c} \\
& f^{\prime}{ }_{1}=1.4 f^{\prime}{ }_{c} \\
& f^{\prime}{ }_{2}=1.75 f^{\prime}{ }_{c}
\end{aligned}
$$

These stress states are only valid for stress states satisfying the condition

$$
\left|\sigma_{h}\right| \leq \sqrt{3} f_{c}^{\prime}
$$

\section{Steel Constitutive Model}

\subsection{Reinforcement Bars}

Material Model Number 3 refers to the Link8 element. The Link8 element is being used for all of the steel reinforcement in the beam and it is assumed to be bilinear isotropic. Bilinear isotropic material is also based on the von Mises failure criteria. The bilinear model requires the yield stress $\left(f_{y}\right)$, as well as the hardening modulus of the steel to be defined. The yield stress was defined as 60,000 psi, and the hardening modulus was 2900 psi. The stress-strain curve 
of the reinforcing bars is assumed to be elastic up to the steel yield stress $\left(f_{y}\right)$, followed by linear hardening up to the steel ultimate strength $\left(f_{u}\right)$ as shown in Figure 6.

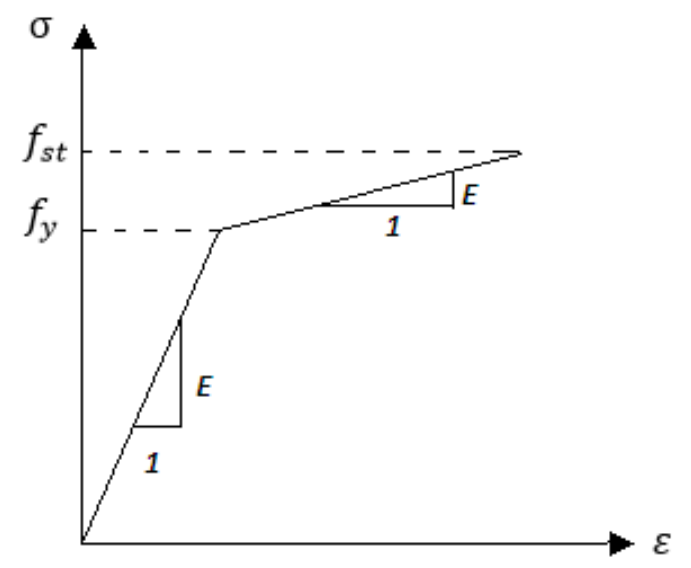

Figure 6. Uniaxial stress-strain relation for steel [19]

\subsection{Steel Plate}

Material Model Number 2 refers to the Solid45 element. The Solid45 element is being used for the steel plates at the loading points and the supports on the beam. Therefore, this element is modeled as a linear isotropic element with a modulus of elasticity for the steel $\left(\mathrm{E}_{\mathrm{s}}\right)$, and the Poisson's ratio (0.3).

Table 1. Material Models

\begin{tabular}{|c|c|c|c|}
\hline Material & Element Type & Mater & \\
\hline \multirow{10}{*}{ Concrete 1} & \multirow{10}{*}{ Solid 65} & \multicolumn{2}{|c|}{ Linear Isotropic } \\
\hline & & $\mathrm{E}$ & 3949076 Psi \\
\hline & & $\mathrm{v}$ & 0.3 \\
\hline & & \multicolumn{2}{|c|}{ Multi-linear Isotropic } \\
\hline & & Strain & Stress Psi \\
\hline & & 0.00036 & 1421.7 \\
\hline & & 0.0006 & 2233 \\
\hline & & 0.0013 & 3991 \\
\hline & & 0.0019 & 4656 \\
\hline & & 0.00243 & 4800 \\
\hline \multirow{6}{*}{ Steel Reinforcement 2} & \multirow{6}{*}{ Link 8} & \multicolumn{2}{|c|}{ Linear Isotropic } \\
\hline & & $\mathrm{E}$ & 29000000 Psi \\
\hline & & $\mathrm{v}$ & 0.3 \\
\hline & & \multicolumn{2}{|c|}{ Bilinear Isotropic } \\
\hline & & Yield Stress & 60000 Psi \\
\hline & & Tangential Modulus & 2900 Psi \\
\hline \multirow{3}{*}{ Steel Plate 3} & \multirow{3}{*}{ Solid 45} & \multicolumn{2}{|c|}{ Linear Isotropic } \\
\hline & & $\mathrm{E}$ & 29000000 Psi \\
\hline & & $\mathrm{v}$ & 0.3 \\
\hline
\end{tabular}

\subsection{FE Modeling of Steel Reinforcement}

Tavarez [20], discusses three techniques that exist to model steel reinforcement in finite element models for reinforced concrete (Figure 7): the discrete model, the embedded model, and the smeared model. The reinforcement in the discrete model (Figure 7a) uses bar or beam elements that are connected to concrete mesh nodes. Therefore, the concrete and the reinforcement mesh share the same nodes and concrete occupies the same regions occupied by the reinforcement. A drawback to this model is that the concrete mesh is restricted by the location of the reinforcement and the volume of the mild-steel reinforcement is not deducted from the concrete volume. 
The embedded model (Figure 7b) overcomes the concrete mesh restriction(s) because the stiffness of the reinforcing steel is evaluated separately from the concrete elements. The model is built in a way that keeps the reinforcing steel displacements compatible with the surrounding concrete elements. When reinforcement is complex, this model is very advantageous. However, this model increases the number of nodes and degrees of freedom in the model, therefore, increasing the run time and computational cost. The smeared model (Figure 7c) assumes that reinforcement is uniformly spread throughout the concrete elements in a defined region of the FE mesh. This approach is used for large-scale models where the reinforcement does not significantly contribute to the overall response of the structure.
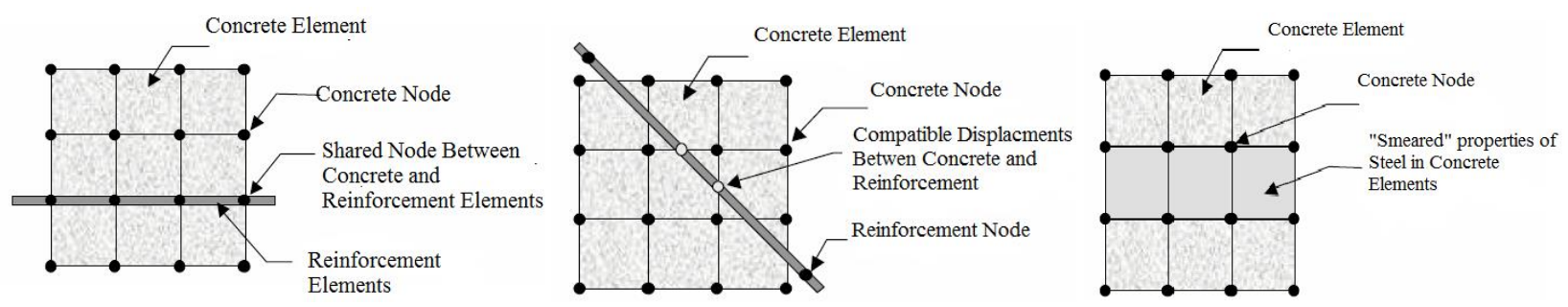

Figure 7. Model for reinforcement in reinforced concrete [20]: (a) discrete model; (b) embedded; and (c) smeared

\section{Finite Element Analysis}

Experimental testing is widely carried out to study individual structural elements and the concrete strength under different loading conditions. This method gives the actual behavior of the structure. However, this takes time and is quite expensive. Recently, the Finite Element Analysis (FEA) method has been used for the evaluation of structures, providing an accurate prediction of the structural elements subjected to different types of structural loading. Since the FEA method is much faster than the experimental work and is cost effective, this method has become the preferred method to study the behavior of concrete elements.

\subsection{Geometry of the Beam}

The geometry of the full size beam is shown in Figure 8. The total length of the span between the two supports is 15 feet. The beam is considered as being simply supported by providing roller support on both sides. The beam is subjected to two point loads at the midspan of the beam. The details of the RC beam are shown in Figure 9.

\subsection{Material Property}

Concrete material has a brittle behavior and exhibits different behavior when under compression and tension. The concrete material is considered to be linear isotropic, and multi-linear isotropic material properties are used to properly model concrete. Steel Reinforcement Material is considered to be both a linear isotropic and a bilinear isotropic material, while the Steel Plate is a Linear isotropic. The ANSYS program requires the uniaxial stress-strain relationship for concrete under compression. The Solid65 element requires linear isotropic and multi-linear isotropic material properties to properly model concrete. The multi-linear isotropic material uses the Von-Misses failure criterion, along with the Willam and Warnke (1974) model to define the failure of the concrete. The simplified stress strain relationship for concrete under compression was obtained and is shown in Figure 4. The parameters needed to define the material models can be found in Table 1. As seen in Table 1, there are multiple parts of the material model for each element. The Solid65 element was used to model the concrete. This element has eight nodes with three degrees of freedom at each node translations in the nodal $\mathrm{x}, \mathrm{y}$, and $\mathrm{z}$ directions. This element is capable of plastic deformation, cracking in three orthogonal directions, and crushing. Solid45 element was used for steel plates at the supports for the beam. This element has eight nodes with three degrees of freedom at each node - translations in the nodal $\mathrm{x}, \mathrm{y}$, and $\mathrm{z}$ directions. A Link8 element was used to model steel reinforcement. This element is a $3 \mathrm{D}$ spar element which has two nodes with three degrees of freedom - translations in the nodal $\mathrm{x}, \mathrm{y}$, and $\mathrm{z}$ directions. This element is also capable of plastic deformation.

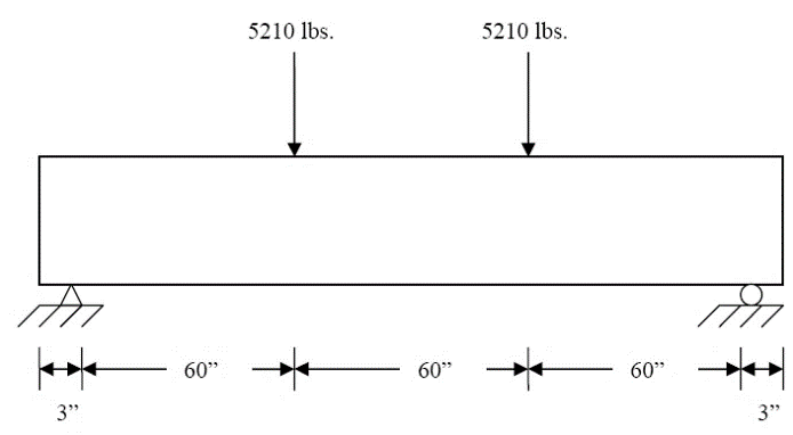

Figure 8. Geometry of the control beam 


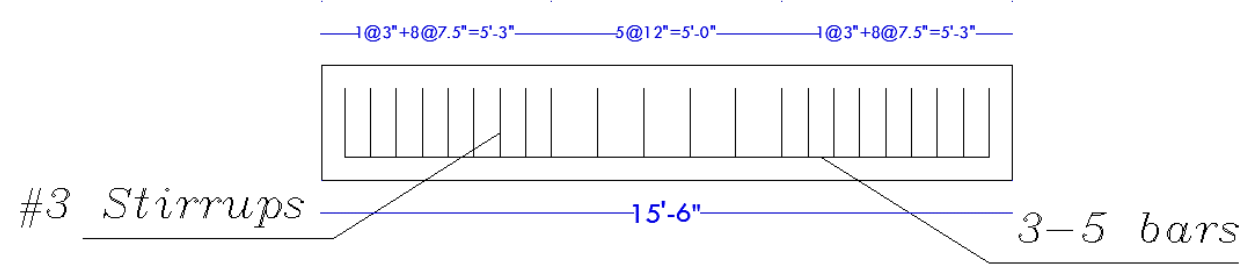

Figure 9. Typical details for control beam reinforcement

\subsection{Finite Element Modeling}

Due to symmetry, only a quarter of the beam was modeled in order to save computation time. The support is a $3 \times 5 \times 1$ in. steel plate, while the plate at the load point is $6 \times 5 \times 1 \mathrm{in}$. The combined volumes of the plate, support, and beam are shown in Figure 10. The FE mesh for the beam model is shown in Figure 8. To obtain good results from the Solid65 element, the use of a rectangular mesh is recommended. Therefore, the mesh was set up such that either square or rectangular elements were created (Figure 11). The volume sweep command was used to mesh the steel plate and the support. This properly sets the width and length of the elements in the plates to be consistent with the elements and nodes in the concrete portions of the model. The overall mesh of the concrete, plate, and support volumes is shown in Figure 11. The necessary element divisions are noted. The meshing of the reinforcement is a special case compared to the volumes. However, the necessary mesh attributes, as described above, need to be set before each section of the reinforcement is created. Link8 elements were used to create the flexural and shear reinforcement. Reinforcement exists at a plane of symmetry and in the beam. The area of steel at the plane of symmetry is one half the normal areas for a \#5 bar because one half of the bar is cut off. Shear stirrups are modeled throughout the beam. Only half of the stirrup is modeled because of the symmetry of the beam. Figure 12 illustrates that the rebar shares the same nodes at the points that it intersects the shear stirrups.

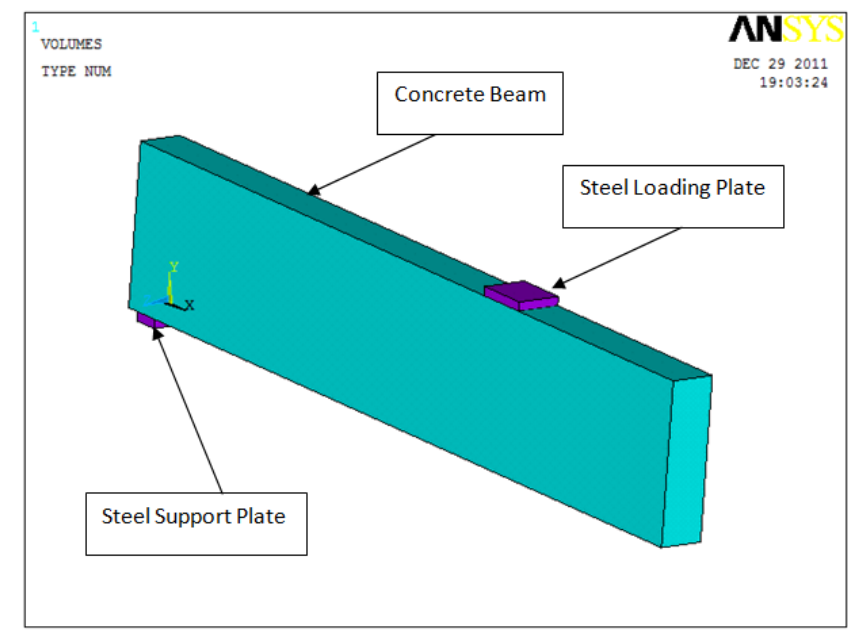

Figure 10. Volumes created in ANSYS

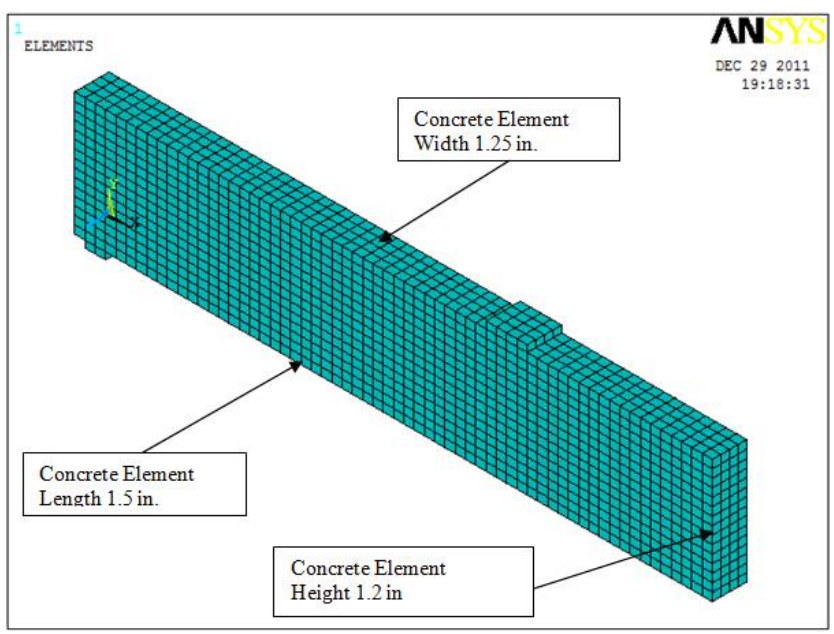

Figure 11. Meshes of the concrete, steel plate, and steel support 


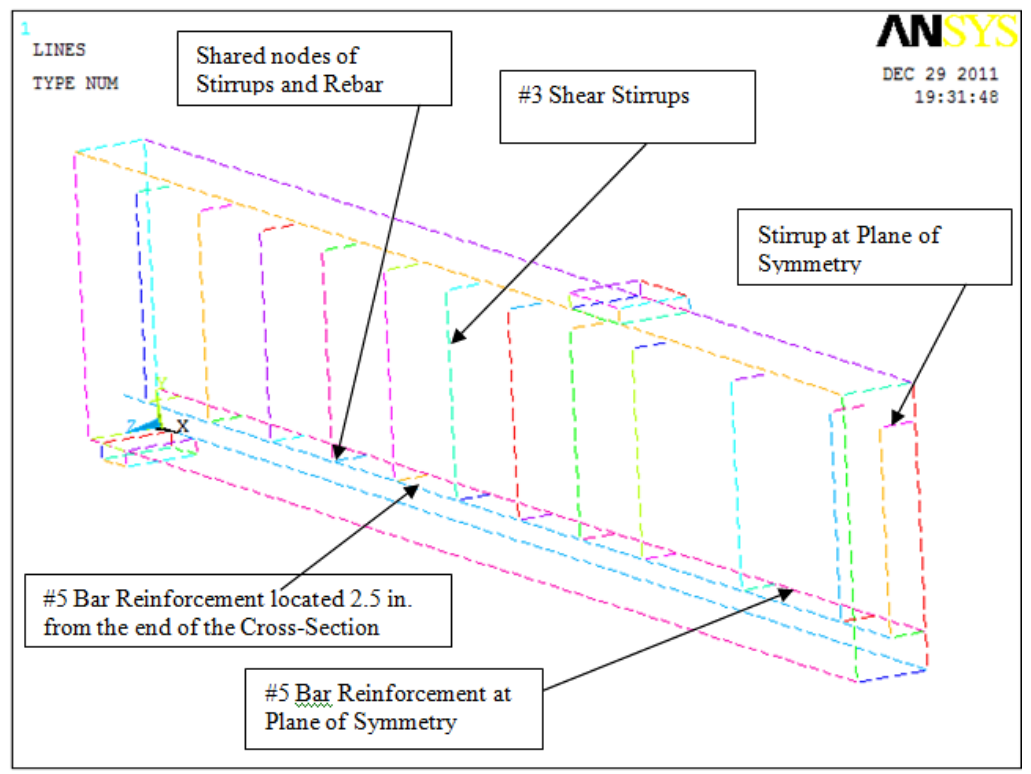

Figure 12. Reinforcement configuration

\subsection{Loads and Boundary Conditions}

Displacement boundary conditions are needed to constrain the model in order to get a unique solution. To ensure that the model acts the same way as the experimental beam, boundary conditions need to be applied at the points of symmetry, and where the supports and loadings exist. The symmetry boundary conditions were set first. The model being used is symmetric about two planes. Nodes defining a vertical plane through the beam cross-section centroid define a plane of symmetry. To model the symmetry, nodes on this plane must be constrained in the perpendicular direction. These nodes, therefore, have a degree of freedom constraint $\mathrm{UX}=0$. Second, all nodes selected at $\mathrm{Z}=0$ define another plane of symmetry. These nodes were given the constraint $\mathrm{UZ}=0$. The support was modeled in such a way that a roller was created. A single line of nodes on the plate were given constraint in the UY, and UZ directions, and applied as constant values of 0 . By doing this, the beam is allowed to rotate at the support. The force, $\mathrm{P}$, applied at the steel plate is applied across the entire centerline of the plate. The force applied at each node on the plate is one tenth of the actual force applied. Figure 13 illustrates the load and boundary conditions for the beam.

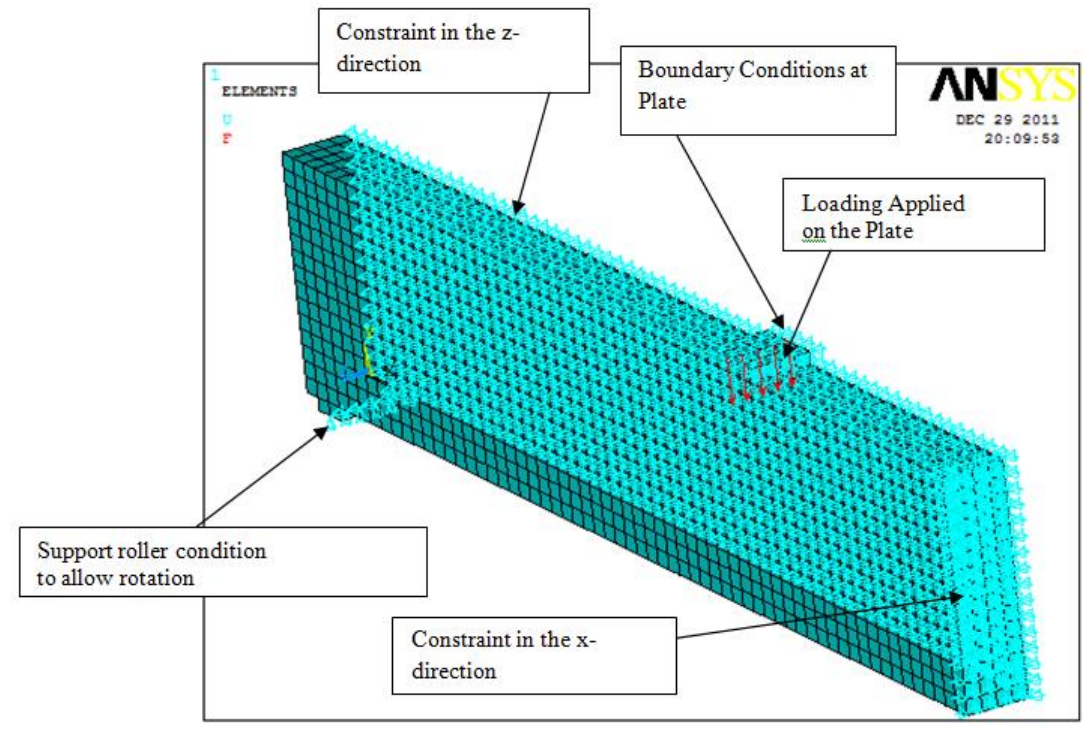

Figure 13. Load and boundary conditions

\section{Results and Discussions}

The FE analysis of the model was set up to examine three different behaviors: initial cracking of the beam, yielding of the steel reinforcement, and the strength limit state of the beam. The application of the loads up to failure was done incrementally. After each load increment was applied, the restart option was used to go to the next step after convergence. 
The time at the end of each load step corresponds to the loading applied. For the first load step the time at the end of the load step is 5210 referring to a load of, P, of $5210 \mathrm{lbs}$ applied at the steel plate. The two convergence criteria used for the analysis were Force and Displacement. These criteria were left at the default values up to 5210 lbs. However, when the beam began cracking, convergence for the non-linear analysis was impossible with the default values. The displacements converged, but the forces did not. Therefore, the convergence criterion for force was dropped and the reference value for the Displacement criteria was changed to 5. This value was then multiplied by the tolerance value of 0.05 to produce a criterion of 0.25 during the nonlinear solution for convergence. A small criterion must be used to capture the correct response. This criteria was used for the remainder of the analysis. The steps taken up to the initial cracking of the beam can be decreased to one load increment to model/capture the initial cracking. Once initial cracking of the beam has begun $(5220 \mathrm{lbs})$, the load increments were increased slightly until subsequent cracking of the beam $(14,000 \mathrm{lbs})$. Once the yielding of the reinforcing steel is reached, the load increments must be decreased again. Yielding of the steel occurs at a load step of 13,350; therefore, the load increment sizes begin decreasing further because displacements are increasing more rapidly. Eventually, the load increment size is decreased to $2 \mathrm{lb}$. to capture the failure of the beam. Failure of the beam occurs when convergence fails with this very small load increment. The load deformation trace produced by the analysis confirmed the failure load. The result from FE analysis of the model for the three different behaviors: initial cracking of the beam, yielding of the steel reinforcement, and the strength limit state of the beam are shown in Figure 14.

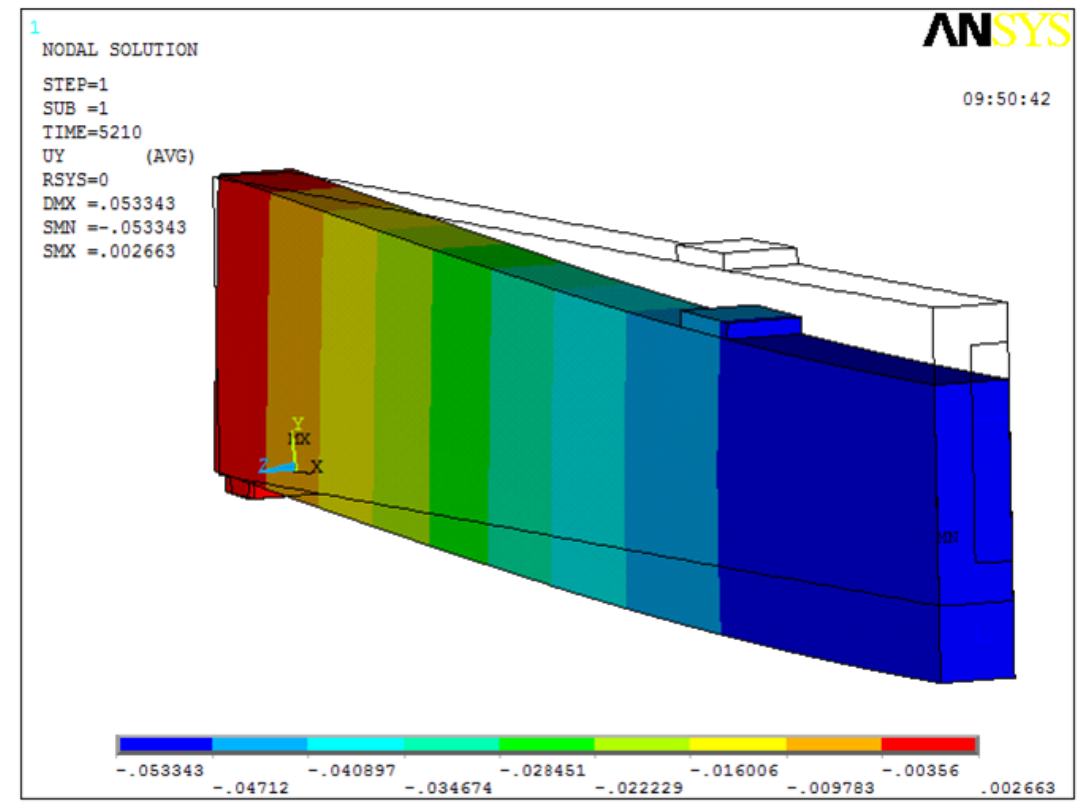

a- Deflection at mid-span for beam at the 5210 loads step

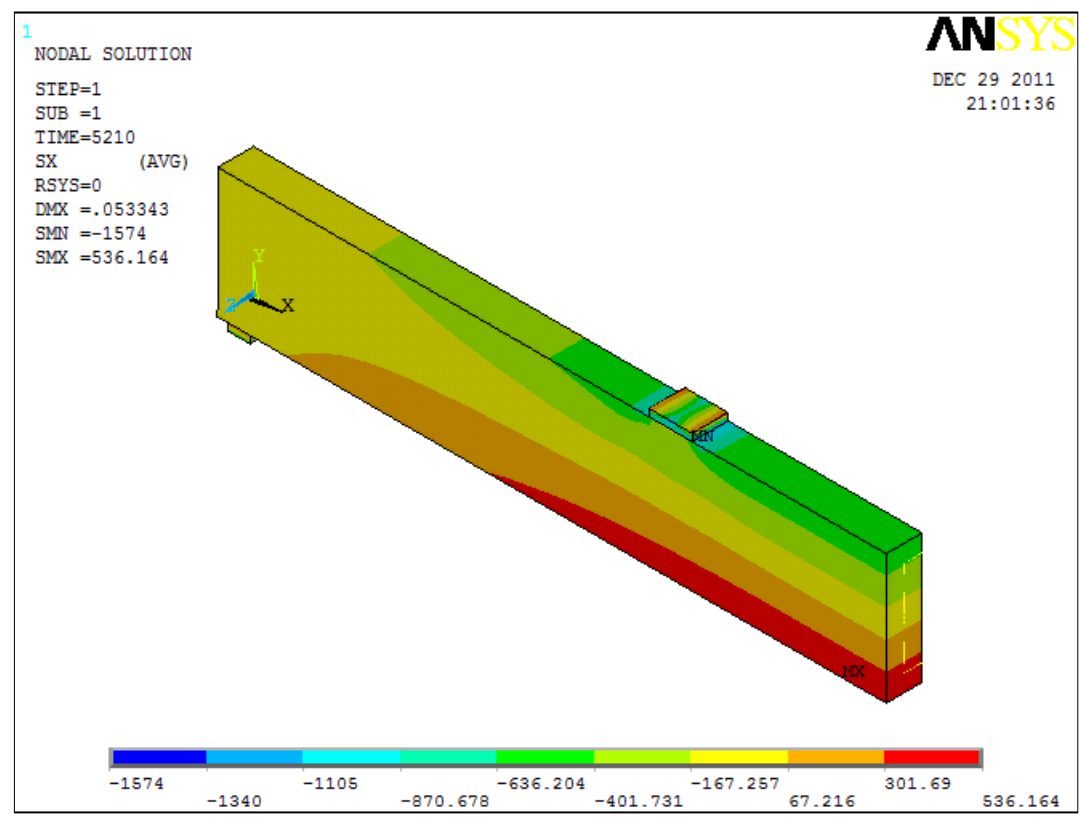

b- Concrete Stress at the extreme tension fiber 


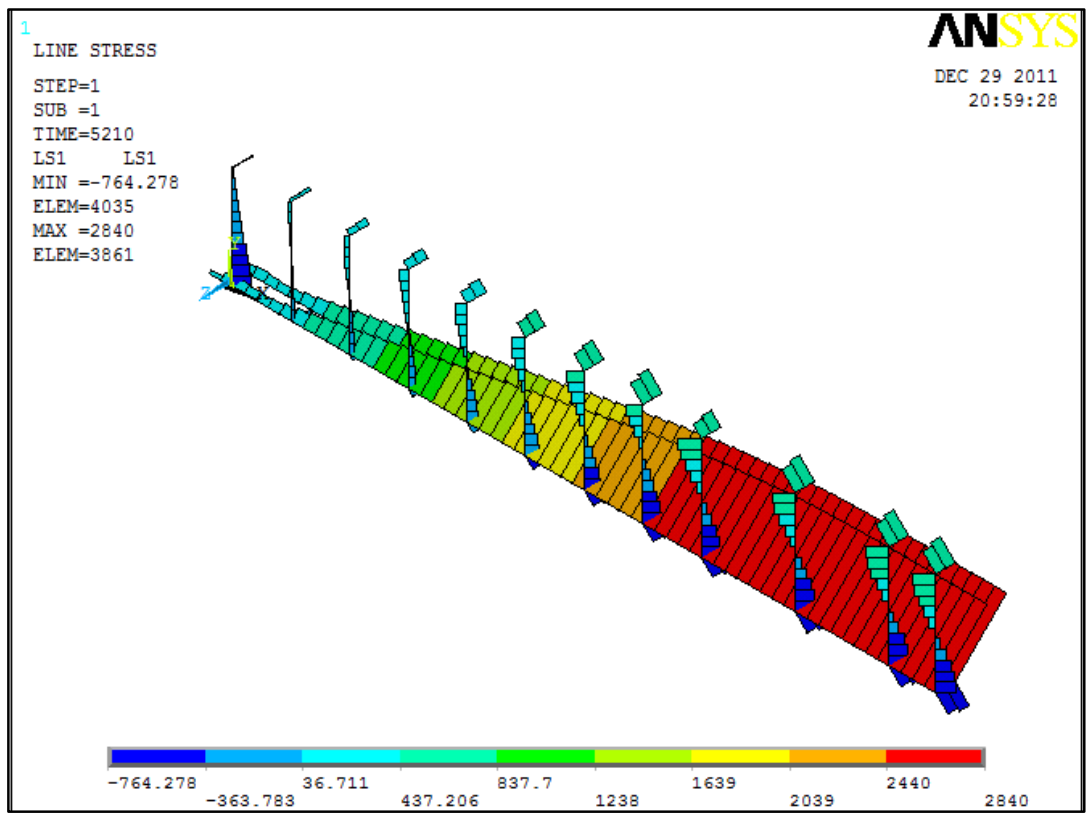

c- Steel Stress at the 5210 load step

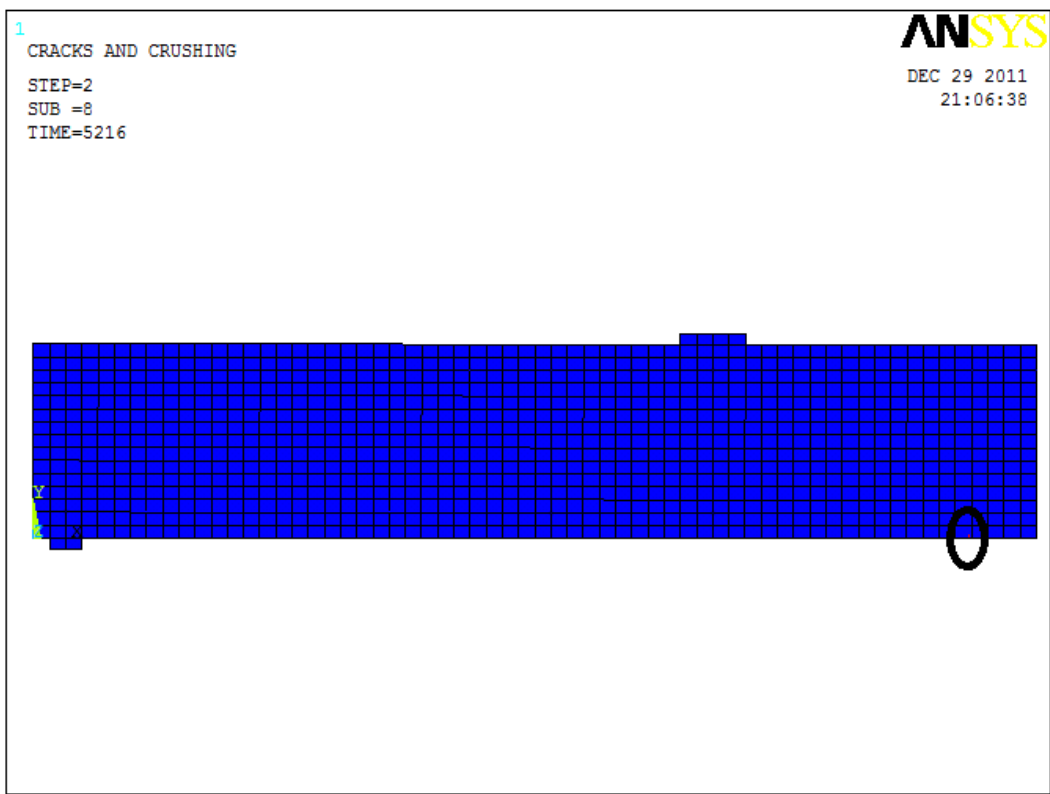

d- 1st Crack of the Concrete Model

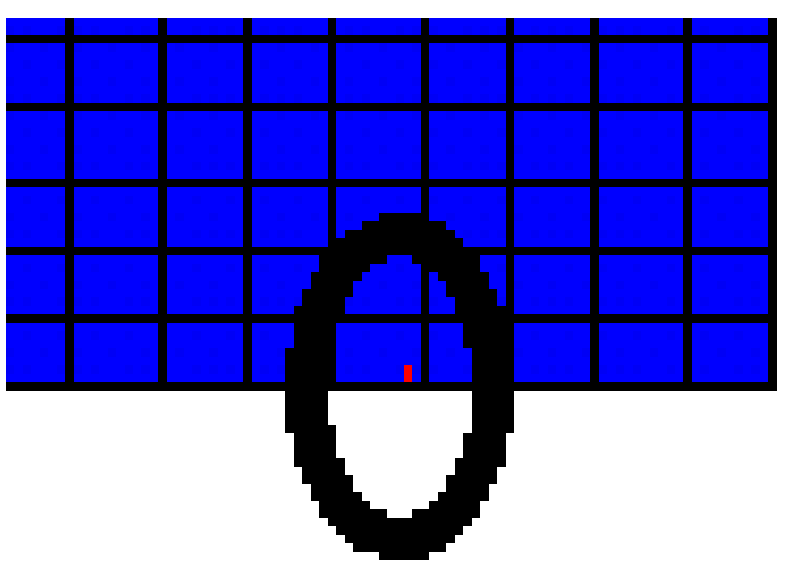

e- Concrete Stress at the crack load 


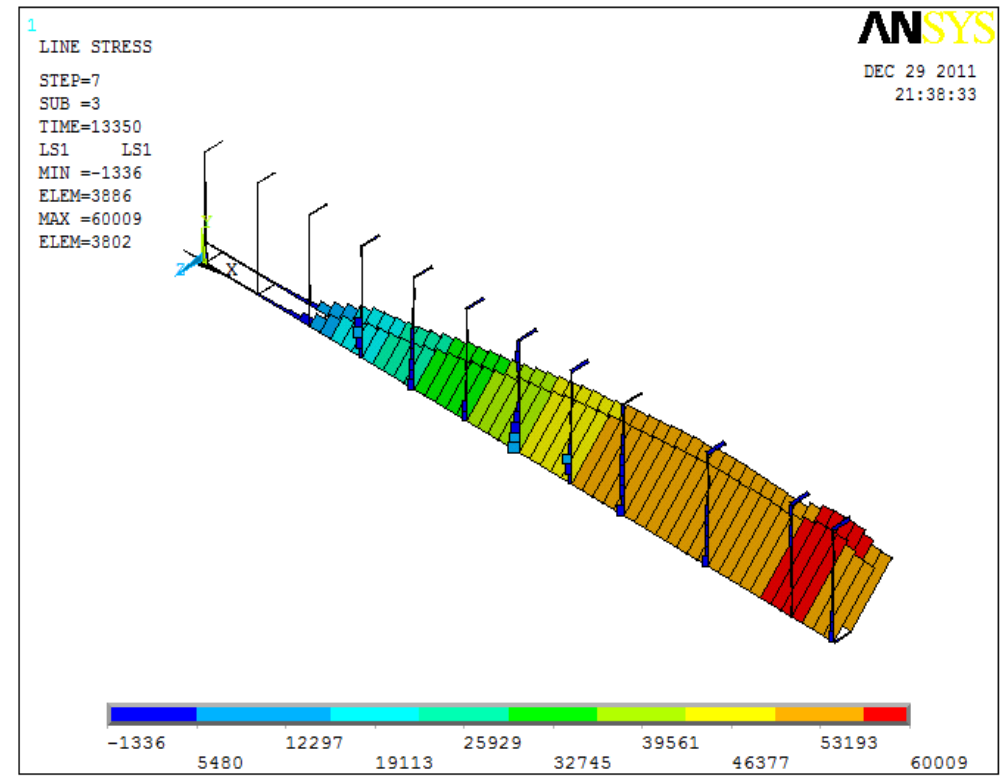

f- Yielding stress of reinforcement

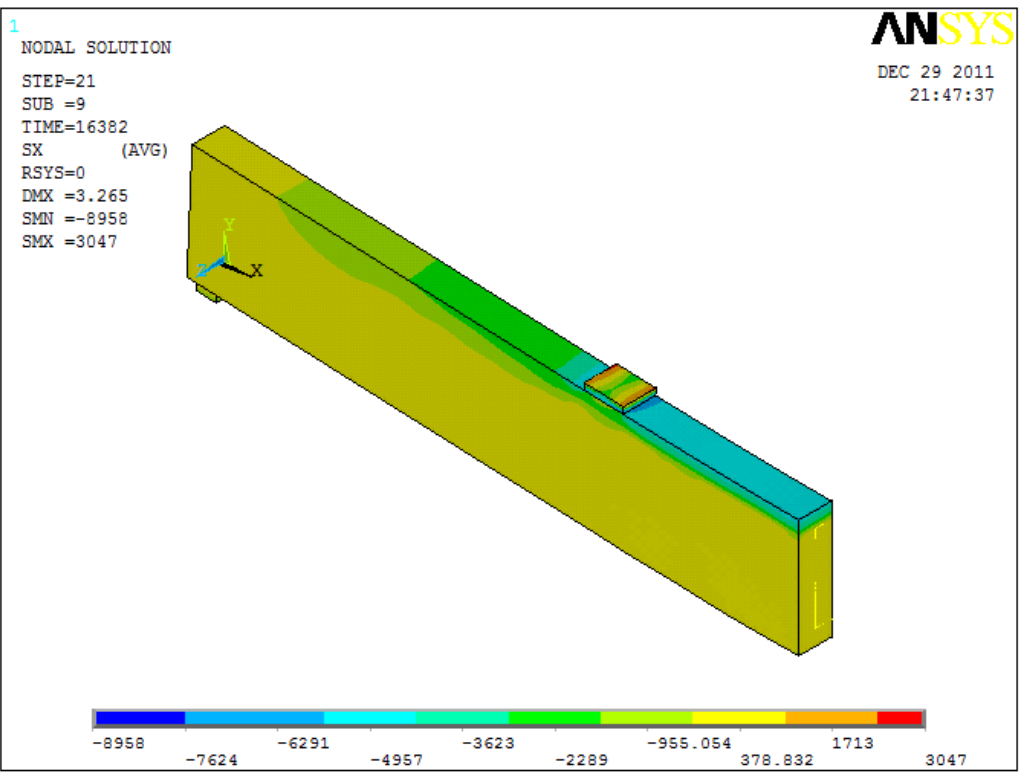

g- Concrete Stress at Failure load Beam

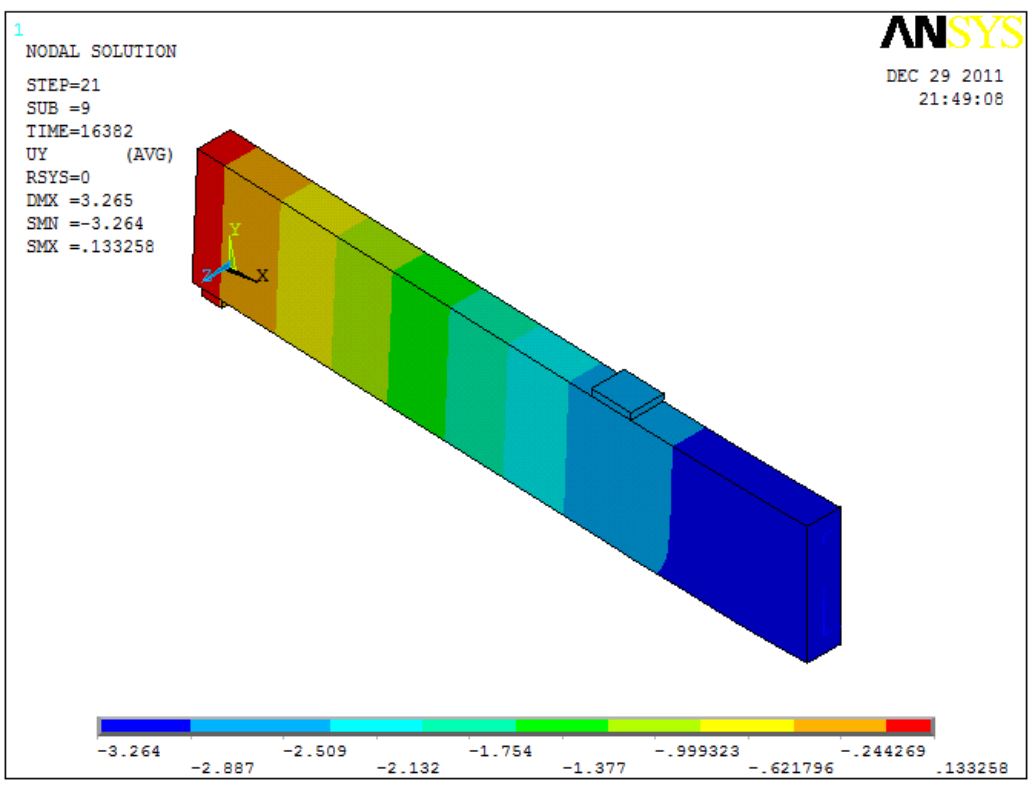

h- Deflection at Failure Load 

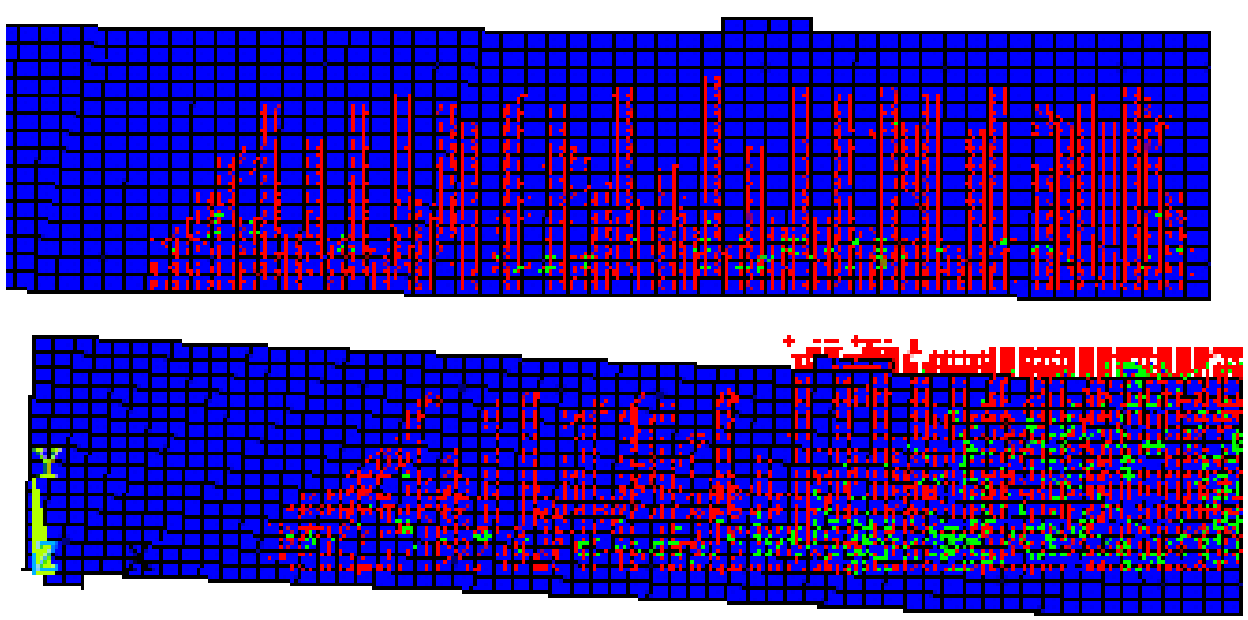

i- Failure of the concrete beam

Figure 14. a)- Deflection at mid-span for beam at the 5210 loads step b)- Concrete Stress at the extreme tension fiber, c) - Steel Stress at the 5210 load step, d) - 1st Crack of the Concrete Model, e) - Concrete Stress at the crack load, f) - Yielding stress of reinforcement, g) - Concrete Stress at Failure load Beam, h) - Deflection at Failure Load, i) - Failure of the Concrete Beam

The linear region can be analyzed based on the design for flexure given in MacGregor [15], for a reinforced concrete beam. The comparisons were made in this region to ensure that deflections and stresses were consistent with the FE model and the beam before cracking occurred. The results in Table 2 indicate that the FE analysis of the beam prior to cracking is acceptable. The following equations were used for the Hand Calculation at load step 5210.

The modulus of elasticity of the concrete

$$
E_{c}=57000 \sqrt{f_{c}^{\prime}}
$$

The modulus of rupture

$$
E_{c}=7.5 \sqrt{f_{c}^{\prime}}
$$

The stress at the extreme tension fiber is then calculated

$$
f_{c t}=\frac{M y}{I}
$$

The stress in the steel at this point is calculated

$$
f_{c t}=\frac{M y}{I} \eta
$$

The deflection at the centerline of the concrete beam at load $5210 \mathrm{lbs}$;

$$
\Delta_{\max }=\frac{P a}{24 E I}\left(3 l^{2}-4 a^{2}\right)
$$

Table 2. Deflection and stress compression at first cracking

\begin{tabular}{ccccc}
\hline Model & $\begin{array}{c}\text { Extreme tension fiber stress } \\
\text { (Psi) }\end{array}$ & $\begin{array}{c}\text { Reinforcement steel } \\
\text { stress (Psi) }\end{array}$ & Deflection (in) & $\begin{array}{c}\text { Load at first Crack } \\
\text { (Psi) }\end{array}$ \\
\hline Hand Calculation & 530 & 3024 & 0.0529 & 5118 \\
ANSYS & 536 & 2840 & 0.0534 & 5216 \\
\hline
\end{tabular}

The full nonlinear load-deformation response can be seen in Figure 15. This load-deformation curve fits to the curve from Buckhouse [13]. The response calculated using FEA is plotted upon the experimental response from Buckhouse [13]. The entire load-deformation response produced by the model compares well with the response from Buckhouse [13]. This gave confidence in the use of ANSYS and the model developed. 


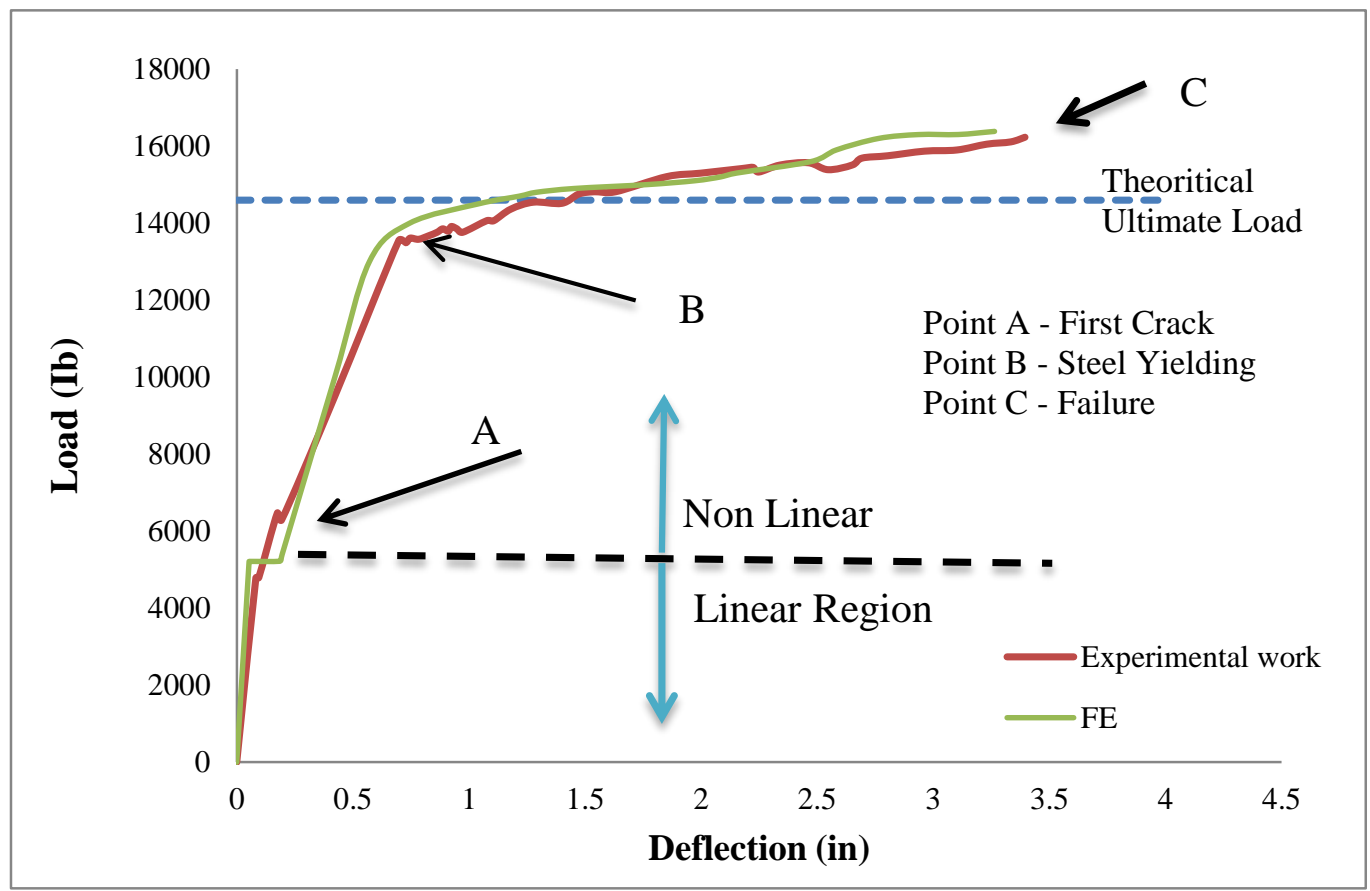

Figure 15. Loads vs. Deflection curve for Buckhouse beam [13]

\section{Conclusion}

In this research work a study of reinforced concrete beams was conducted using finite element analysis in order to understand the response of reinforced concrete beams due to transverse loading. The reinforced concrete beam with flexural and shear reinforcement was analyzed to failure and compared to experimental results. A multi-linear isotropic material uses the Von-Misses failure criterion, along with the Willam and Warnke (1974) model to define the failure of the concrete, by using the solid65 element and crushing. The solid 45 element was used for the steel plates at the supports of the beam. For the reinforcement material a linear isotropic and bilinear isotropic material, with a Link8 element, was used to model the steel reinforcement. The following conclusions can be stated based on an evaluation of the analyses of the FE model for concrete beams. (1) Deflections and stresses at the centerline, along with initial and progressive cracking of the finite element model, compare well to the analytical model based on the energy method and the experimental data obtained from a reinforced concrete beam. (2) The failure mechanism of a reinforced concrete beam is modeled quite well using FEA, and the failure load predicted is very close to the failure load measured during experimental testing. It is also worth mentioning that in such a numerical solution a possible error of the analysis may occur.

\section{Acknowledgement}

The authors gratefully acknowledge the help of the staff at the engineering computer laboratory at Fahad Bin Sultan University in conducting the model simulation.

\section{Conflicts of Interest}

The authors declare no conflict of interest.

\section{References}

[1] Genikomsou, Aikaterini S., and Maria Anna Polak. "Finite Element Analysis of Punching Shear of Concrete Slabs Using Damaged Plasticity Model in ABAQUS.” Engineering Structures 98 (September 2015): 38-48. doi:10.1016/j.engstruct.2015.04.016.

[2] Chacón, Rolando. "Circular Concrete-Filled Tubular Columns: State of the Art Oriented to the Vulnerability Assessment." The Open Civil Engineering Journal 9, no. 1 (May 28, 2015): 249-259. doi:10.2174/1874149501509010249.

[3] Aghajanzadeh, S.M., and H. Mirzabozorg. "Concrete Fracture Process Modeling by Combination of Extended Finite Element Method and Smeared Crack Approach." Theoretical and Applied Fracture Mechanics 101 (June 2019): 306-319. doi:10.1016/j.tafmec.2019.03.012.

[4] Halahla, Abdulsamee. "Study the Behavior of Reinforced Concrete Beam Using Finite Element Analysis." Proceedings of the 3rd World Congress on Civil, Structural, and Environmental Engineering (April 2018). doi:10.11159/icsenm18.103. 
[5] El-Khoriby, Saher, Mohammed A. Sakr, Tarek M. Khalifa, and Mohammed M. Eladly. "Modelling and Behaviour of Beam-toColumn Connections under Axial Force and Cyclic Bending.” Journal of Constructional Steel Research 129 (February 2017): 171-184. doi:10.1016/j.jcsr.2016.11.006.

[6] Kaspar J. Willam, Tadaaki Tanabe "Finite Element Analysis of Reinforced Concrete Structures.” ACI International (2001), ISBN: $087031064 X, 9780870310645$.

[7] Shing, P. Benson, and Tada-aki Tanabe, eds. "Modeling of inelastic behavior of RC structures under seismic loads." ASCE Publications, 2001.

[8] Kaya, Mustafa, and A. Samet Arslan. “Analytical Modeling of Post-Tensioned Precast Beam-to-Column Connections.” Materials \& Design 30, no. 9 (October 2009): 3802-3811. doi:10.1016/j.matdes.2009.01.033.

[9] Willam K.J., and Warnke E.P. “Constitutive Model for Triaxial Behaviour of Concrete”, Seminar on Concrete Structures Subject to Triaxial Stresses. International Association of Bridge and Structural Engineering Conference, Bergamo, Italy. 1974.

[10] Niroomandi, A., A. Maheri, Mahmoud R. Maheri, and S.S. Mahini. "Seismic Performance of Ordinary RC Frames Retrofitted at Joints by FRP Sheets.” Engineering Structures 32, no. 8 (August 2010): 2326-2336. doi:10.1016/j.engstruct.2010.04.008.

[11] Ravi, Robert S., and Prince G. Arulraj. "Finite element modeling on behavior of reinforced concrete beam-column joints retrofitted with carbon fiber reinforced polymer sheets." International journal of civil and structural engineering 1, no. 3 (2010): 576.

[12] Hawileh, R.A., M. Naser, W. Zaidan, and H.A. Rasheed. "Modeling of Insulated CFRP-Strengthened Reinforced Concrete TBeam Exposed to Fire.” Engineering Structures 31, no. 12 (December 2009): 3072-3079. doi:10.1016/j.engstruct.2009.08.008.

[13] Shaker, Qassim M., and Hayder H. H . Kamonna. "Nonlinear Analysis of Reinforced Concrete Beams Strengthened by Prestressed CFRP Sheets Under Static Loads.” Jordan Journal of Civil Engineering 10, no. 1 (January 1, 2016): 93-106. doi:10.12816/0024654.

[14] Buckhouse E.R. "External Flexural Reinforcement of Existing Reinforced Concrete Beams Using Bolted Steel Channels." Master's Thesis, Marquette University, Milwaukee, Wisconsin (1997).

[15] MacGregor, James Grierson, James K. Wight, Susanto Teng, and Paulus Irawan. "Reinforced Concrete: Mechanics and Design." Vol. 3. Upper Saddle River, NJ: Prentice Hall, 1997.

[16] Guide, ANSYS FLUENT User'S. “Ansys.” Inc. Release 14 (2011).

[17] Kachlakev, Damian, Ted R. Miller, S. Yim, K. Chansawat, and T. Potisuk. "Finite Element Modeling of Concrete Structures Strengthened with FRP Laminates.” No. FHWA-OR-RD-01-17. Oregon. Dept. of Transportation. Research Section, 2001.

[18] Desai Y.M., Mufti A.A., and Tadros G. “User manual for FEM PUNCH, Version 2.0.” ISIS Canada (2002).

[19] SAS ANSYS 10.0. (2005). "Finite Element Analysis System”. SAS IP, Inc., U.S.A.

[20] Tavárez, Federico A. "Simulation of Behavior of Composite Grid Reinforced Concrete Beams Using Explicit Finite Element Methods." University of Wisconsin--Madison, 2001. 